DOI: $10.5216 /$ cab.v13i3.18439

\title{
DETECÇÃO MOLECULAR DE Babesia canis vogeli EM CÃES E EM Rhipicephalus sanguineus NA MESORREGIÃO DO OESTE MARANHENSE, NORDESTE BRASILEIRO
}

\author{
Arannadia Barbosa Silva ${ }^{1}$, ANDrÉa PEREIRA Costa ${ }^{2}$, JoICy CORTEZ de SÁ ${ }^{3}$, Francisco Borges \\ COSTA $^{2}$, ANA Clara GOMES dos SANTOS ${ }^{4}$, Rita DE MARIA SEABRA NoGUEIRA DE CANDANEDO GUERRA ${ }^{4 *}$ \\ ${ }^{1}$ Pós Graduanda em Ciência Animal da Universidade Estadual do Maranhão - UEMA, São Luís, MA, Brasil \\ ${ }^{2}$ Pós Graduandos da Faculdade de Medicina Veterinária e Zootecnia da Universidade de São Paulo - USP, São Paulo, SP, Brasil. \\ ${ }^{3}$ Pós Graduanda do Programa da Rede Nordeste em Biotecnologia - RENORBIO, São Luís, MA, Brasil. \\ ${ }^{4 *}$ Professoras do Programa de Pós-graduação em Ciência Animal da Universidade Estadual do Maranhão - UEMA, São Luís, MA, Brasil - \\ grita62@hotmail.com
}

Objetivou-se determinar a ocorrência de Babesia canis vogeli em cães e no carrapato vetor de ambiente urbano e rural da microrregião de Imperatriz, mesorregião do Oeste Maranhense, verificando-se os possíveis fatores de risco associados à infecção por esse agente. Foram coletadas amostras de sangue e espécimes de carrapatos de 300 cães provenientes da área urbana e rural da microrregião de Imperatriz. Foram realizadas extração do DNA do sangue e dos carrapatos. Posteriormente, as amostras foram submetidas a ensaios de reação em cadeia pela polimerase, utilizando-se oligonucleotídeos iniciadores subespécieespecífico para $B$. c. vogeli. A PCR a partir de amostras de sangue revelou que $3,33 \%$ (10/300) dos cães estavam positivos para B. c. vogeli, sendo que 1,0\% (3/300) era da área urbana e 2,33\% (7/300) da área rural. Não foram verificadas associações entre ambiente de coleta, grupo racial, sexo e controle de carrapatos; contudo, a taxa de positividade para $B$. $c$. vogeli foi maior entre os cães jovens. Os carrapatos coletados foram identificados como Rhipicephalus sanguineus, sendo seis $(2,56 \%)$ positivos para B. c. vogeli, com 1,28\% (3/235) provenientes de cães da área urbana e 1,28\% (3/235) de cães da área rural. Este estudo confirmou a presença de $B$. c. vogeli em cães e em $R$. sanguineus na área urbana e rural da microrregião de Imperatriz-MA.

PALAVRAS-CHAVE: B. canis vogeli; epidemiologia molecular; PCR; R. sanguineus.

\section{MOLECULAR DETECTION OF Babesia canis vogeli IN DOGS AND IN Rhipicephalus sanguineus FROM THE MIDDLE-WEST REGION OF MARANHÃO, NORTHEAST BRAZIL}

\section{ABSTRACT}

The objective of this study was to determine the occurrence of Babesia canis vogeli in dogs and in the tick vector from urban and rural environment of the microregion of Imperatriz, middle-west of Maranhão, evaluating risk factors associated with infection by this agent. Samples were collected from blood and tick specimens from 300 dogs from urban and rural areas of the microregion of Imperatriz. DNA was extracted from blood samples and ticks, and tested by polymerase chain reaction assays using subspecies-specific initiating oligonucleotides for $B$. $c$. vogeli. PCR from the blood revealed that $3.33 \%(10 / 300)$ of dogs were positive for
B. c. vogeli, and that $1.0 \%(3 / 300)$ came from urban and $2.33 \%$ (7/300) from rural area. No association was verified in relation to the environment, race group, sex and tick control; however young animals were more frequently positive to the infection. Ticks collected were identified as Rhipicephalus sanguineus, and six $(2.56 \%)$ were positive for B. c. vogeli, of which $1.28 \%(3 / 235)$ were collected in the urban area and $1.28 \%$ (3/235) from dogs in rural areas. This study confirmed the presence of $B$. c. vogeli in dogs and in $R$. sanguineus in urban and rural microregion of Imperatriz-MA.

KEYWORDS: B. canis vogeli; molecular epidemiology ; PCR; R. sanguineus. 


\section{INTRODUÇÃO}

A babesiose é uma enfermidade de distribuição cosmopolita de grande importância em cães causada por espécies do gênero Babesia, mais frequentemente por Babesia canis e Babesia gibsoni (DANTAS-TORRES \& FIGUEREDO, 2006). A doença apresenta maior ocorrência em regiões tropicais e subtropicais e é transmitida por carrapatos (CARRET et al., 1999).

Estudos têm demonstrado heterogeneidade entre isolados de Babesia canis vogeli de diferentes regiões geográficas, o que levou à reclassificação da espécie B. canis em três subespécies (Babesia canis canis, Babesia canis rossi e B. c. vogeli), com base na ausência de imunidade cruzada, teste sorológico, especificidade do vetor e filogenia molecular (ZAHLER et al., 1998; CARRET et al., 1999).

Estudos realizados com isolados brasileiros de babesias de cães mostraram que, no Brasil, a babesiose canina é causada predominantemente pela B. c. vogeli (PASSOS et al., 2005; SÁ et al., 2006; DUARTE et al., 2008a) com relatos de ocorrência de B. gibsoni no sul do país (TRAPP et al., 2006a; TRAPP et al., 2006b). No Brasil, o principal vetor de B. c. vogeli é o carrapato Rhipicephalus sanguineus (PASSOS et al., 2005). Nesses carrapatos ocorrem transmissões transovariana e estadial, permitindo a transmissão do protozoário em todos os estágios, sendo as ninfas e os adultos mais eficientes na transmissão (TABOADA, 1991).

$\mathrm{O}$ diagnóstico da babesiose canina geralmente se baseia na identificação dos parasitas no interior dos eritrócitos ou livres no plasma, por microscopia do esfregaço sanguíneo (UNGAR DE SÁ et al., 2007). Entretanto, essa técnica é limitada pela baixa sensibilidade e impossibilidade de se fazer a distinção morfológica precisa entre algumas espécies e subespécies; para isso tem sido aplicada metodologia com base em Biologia Molecular (BIRKENHEUER et al., 2004).

Outros métodos, mais sensíveis, estão sendo cada vez mais utilizados no diagnóstico dessa enfermidade, como a prova da Imunofluorescência Indireta (RIFI) e Ensaio Imunoenzimático (ELISA) (BOOZER \& MACINTIRE, 2003). Esses testes sorológicos são úteis para se identificar animais portadores assintomáticos e diagnosticar infecções crônicas quando o nível de parasitemia geralmente está baixo ou não detectável no esfregaço de sangue periférico (FURUTA et al., 2009); no entanto, eles apenas indicam a exposição ao agente, não informando sobre o estágio atual da infecção (WAGNER et al., 1992). Assim, testes moleculares, especialmente a Reação em Cadeia da Polimerase
(PCR), vêm sendo cada vez mais utilizados em estudos epidemiológicos.

O conhecimento da frequência e distribuição de cães potencialmente portadores de babesias tem valor epidemiológico significativo, principalmente em locais onde o número de cães suscetíveis é alto e carrapatos ixodídeos são amplamente distribuídos, possibilitando que a doença seja facilmente disseminada (YAMANE et al., 1994).

No Maranhão, especificamente na mesorregião do Oeste Maranhense, estudos sobre a infecção por esses parasitas são escassos, embora as condições climáticas sejam favoráveis ao desenvolvimento do carrapato vetor. Diante disso, o presente estudo teve como objetivo determinar a ocorrência de B. c. vogeli em cães e carrapatos vetores de ambiente urbano e rural na microrregião de Imperatriz por meio da PCR, verificando-se os possíveis fatores de risco associados à infecção por esse agente.

\section{MATERIAL E MÉTODOS}

A mesorregião do Oeste Maranhense é formada por três microrregiões: Gurupi, Imperatriz e Pindaré. A microrregião de Imperatriz foi escolhida para a realização deste estudo. Essa região apresenta vegetação variada com características tanto de cerrado como de floresta amazônica, apresentando dois periodos bem definidos: seco e chuvoso.

Foram amostrados, randomicamente, 100 cães nos municípios de Imperatriz, Davinópolis e Governador Edison Lobão, divididos em 50 animais na área urbana e 50 na área rural por município, totalizando 300 animais. A pesquisa foi aprovada pelo Comitê de Ética e Experimentação Animal (CEEA)/UEMA com parecer $\mathrm{N}^{\circ}$ 29/2010.

De cada animal foram coletados $5 \mathrm{~mL}$ de sangue total, em tubos contendo anticoagulante (EDTA), por meio da punção das veias cefálica ou jugular. As amostras foram aliquotadas em duplicata, em microtubos de $1,5 \mathrm{~mL}$ livre de DNase/RNase, identificadas, congeladas à temperatura de $-20^{\circ} \mathrm{C}$ para posterior extração de DNA.

Os cães amostrados foram inspecionados quanto à presença de carrapatos. Os espécimes de carrapatos foram coletados manualmente $\mathrm{e}$ acondicionados, por hospedeiro amostrado, em microtubos livre DNase/RNase e conservados em álcool a 70\%. A identificação foi realizada utilizando-se a chave pictórica modificada de ARAGÃO \& FONSECA (1961) e PRATT (1961).

A pesquisa de B. c. vogeli nas amostras sanguíneas e nos carrapatos foi realizada no Laboratório de Patologia Molecular da Universidade 
Estadual do Maranhão/UEMA, São Luís-MA.

Para a extração de DNA, utilizou-se o kit Wizard $^{\circledR}$ Genomic DNA Purification (PROMEGA), seguindo-se as recomendações do fabricante para $300 \mu \mathrm{L}$ de sangue.

De cada animal infestado por carrapatos, foram escolhidos três exemplares (macho, fêmea e ninfa) para a extração do DNA. Os carrapatos foram retirados do álcool etílico e submetidos à secagem à temperatura ambiente para total evaporação do álcool. Posteriormente, foi extraído o DNA empregando-se isotiocianato de guanidina, de acordo com o protocolo descrito por CHOMEKZYNSKI (1993) e adaptado por SANGIONI et al. (2005).

$\mathrm{Na}$ PCR das amostras de sangue e dos carrapatos para $B$. c. vogeli foram utilizados oligonucleotídeos iniciadores, previamente descritos por DUARTE et al. (2008b), que amplificam uma região de aproximadamente 590 pares de base (pb). $O$ iniciador senso BAB1 (5'-GTG AAC CTT ATC ACT TAA AGG-3') é específico para uma região conservada do gene 18S rRNA de Babesia spp. e o anti-senso BAB4 (5'-CAA CTC CTC CAC GCA ATC G-3), para uma região específica da subunidade maior do rRNA de B. c. vogeli. O programa de amplificação foi realizado em termociclador (Biocycler), consistindo em: desnaturação inicial de $94^{\circ} \mathrm{C}$ durante $2 \mathrm{~min}$, seguida por 35 ciclos de $94^{\circ} \mathrm{C}$ por $30 \mathrm{~s}, 56^{\circ} \mathrm{C}$ durante $30 \mathrm{~s} \mathrm{e} 72^{\circ} \mathrm{C}$ durante $1 \mathrm{~min}$, com uma extensão final de $72^{\circ} \mathrm{C}$ durante $5 \mathrm{~min}$. Os produtos amplificados da reação de PCR foram visualizados, através de um transiluminador ultravioleta, em gel de agarose a 1,5\% (150 mL TBE $0,5 \% ; 2,25 \mathrm{~g}$ agarose UltraPure ${ }^{\mathrm{TM}}$ Agarose
Invitrogen $\left.{ }^{\mathrm{TM}}\right)$ contendo brometo de etídeo $(0,5$ $\mathrm{ug} / \mathrm{mL}$ ). Utilizou-se marcador de peso molecular $1 \mathrm{~Kb}$ Plus DNA Ladder Invitrogen (100 a 12.000 pb).

Os resultados foram analisados através de tabelas de contingências com as diferentes variáveis (área, sexo, faixa etária, raça e controle de carrapatos). A comparação dos dados foi realizada pelo Teste Exato de Fisher e cálculo das Odds Ratio para cada variável, com nível de significância de 5\% $(p<0,05)$. As análises foram realizadas com o auxílio do programa computacional EpiInfo version 3.4.7.

\section{RESULTADOS E DISCUSSÃO}

Durante inspeção, verificou-se que 95 $(31,67 \%)$ cães estavam infestados por carrapatos, dos quais $42(14,0 \%)$ eram da área urbana e $53(17,67 \%)$ da área rural. $R$. sanguineus foi a única espécie de carrapato identificada em ambas a áreas, sendo coletado um total de 369 espécimes (150 machos, 168 fêmeas e 51 ninfas).

Das 300 amostras sanguíneas caninas analisadas pela PCR, 3,33\% (10/300) foram positivas para B. c. vogeli, com bandas visualizadas em $590 \mathrm{pb}$ (Figura 1), sendo 1,0\% (3/300) da área urbana e 2,33\% (7/300) da área rural. Dessas amostras positivas, um animal era proveniente da área rural de Imperatriz e outro animal da área urbana de Governador Edison Lobão, e os oito restantes eram do município de Davinópolis (2 animais da área urbana e 6 da área rural). Não foi observada diferença significativa $(\mathrm{p}>0,05)$ entre presença de $B$. c. vogeli com a área de procedência do animal (Tabela 1).

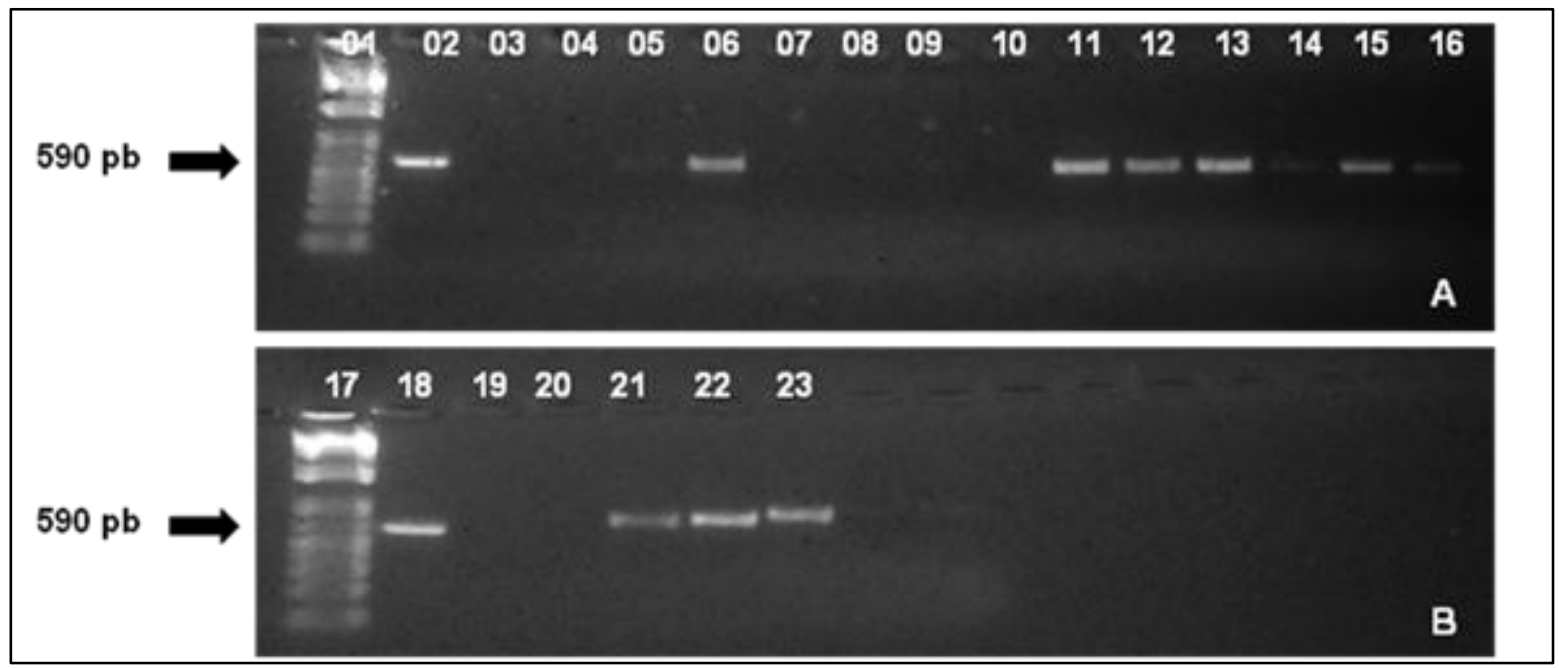

Figura 1: Géis de agarose 1,5\% corado com brometo de etídeo, mostrando produtos de PCR, utilizando os oligonucleotídeos iniciadores BAB1 e BAB4, que amplificam uma região de 590 pb, referente ao gene 18S rRNA, específico para Babesia canis vogeli.

A e B: Linhas 1 e 17: marcador de peso molecular 1Kb; linhas 2 e 18: controle positivo; Linhas 3 e 19: controle negativo; Linhas 4 e 20: controle do Mix; Linhas 6, 11, 12, 13, 14, 15, 16, 21, 22 e 23: correspondem a amostras sanguíneas caninas positivas para B. c. vogeli, coletadas na Microrregião de Imperatriz-MA. 
Este estudo demonstra a presença de $B$. $c$. vogeli em cães provenientes de ambiente urbano e rural na microrregião de Imperatriz. Os métodos moleculares têm contribuído para a delimitação entre as espécies e subespécies de Babesia spp., como descrito em estudos epidemiológicos em diferentes países (ZAHLER et al., 1998; CACCIÓ et al., 2002; MATJILA et al., 2004).

No Brasil, pesquisas sobre os aspectos epidemiológicos em cães de áreas urbanas têm sido realizadas, porém poucos estudos têm sido realizados em áreas rurais (PASSOS et al., 2005; COSTA-JÚNIOR et al., 2009), principalmente comparando-se as duas áreas. Trabalhos dessa natureza são escassos no Maranhão (ROCHA et al., 2011). Estudos no Brasil utilizando-se métodos moleculares relataram a presença de infecção por Babesia spp. em $8 \%$ dos cães de áreas rurais do estado de São Paulo (O’DWYER et al., 2009). Na região Nordeste, RAMOS et al. (2010) observaram positividade de $7,31 \%$ de animais por PCR para $B$. c. vogeli em Pernambuco.

Os resultados obtidos no presente estudo permitem afirmar que os animais dos ambientes urbano e rural têm chances iguais de adquirirem a infecção, uma vez que não houve diferença significativa entre os animais positivos nos ambientes estudados. A ausência de diferença significativa entre presença de $B$. c c vogeli nos ambientes rural e urbano pode ser justificada pela ocorrência de $R$. sanguineus, principal transmissor da B. c. vogeli no Brasil, nos cães de ambos os ambientes. É possível que esse fato esteja relacionado ao número considerável de cães terem seus locais de repouso junto às residências dos proprietários, favorecendo, assim, infestações por $R$. sanguineus. Esse carrapato apresenta hábito nidícola, gerando uma condição ecológica favorável ao parasitismo nos cães, mesmo que o cão esteja em ambiente rural. SZABÓ et al. (2001) também observaram ocorrência de $R$. sanguineus tanto em cães de áreas urbanas quanto rurais. SHIMADA et al. (2003) observaram que o $R$. sanguineus também esteve associado a infestações em áreas urbanas e suburbanas. $\mathrm{O}$ presente estudo mostrou que os animais de ambas as áreas estão expostos à infecção por B. c. vogeli, visto que o parasita e o vetor se fazem presentes na região.

Não foi observada diferença significativa ( $p>0,05)$ entre presença de B. c. vogeli com as variáveis sexo, grupo racial e controle de carrapatos (Tabela 1). Em relação à faixa etária, observou-se que não houve diferença significativa entre animais com idade inferior a 12 meses em comparação a animais com idade entre 1 a 3 anos. No entanto, houve diferença significativa $(p<0,05)$ de animais com idade inferior a 12 meses quando comparados com animais com idade superior a 3 anos. Dessa forma, os animais com idade inferior a 12 meses apresentaram uma chance maior $(\mathrm{OR}=8,06)$ de apresentar a infecção por B. $c$. vogeli detectável por PCR, quando comparados aos animais com idade superior a 3 anos (Tabela 1). Por esse motivo, a idade inferior a 12 meses foi considerada um fator de risco para a infecção por B. c. vogeli. Os resultados aqui apresentados concordam com TABOADA \& MERCHANT (1997), visto que a idade é um importante determinante de resistência, e que os cães jovens são mais susceptíveis à infecção por babesia do que os adultos. Entretanto, outros trabalhos demonstraram que, geralmente, não há diferença estatística em relação á idade (BOBADE et al., 1989; UNGAR DE SÁ et al., 2007).

Com relação às variáveis sexo, grupo racial e controle de carrapatos, observou-se que os animais, independentemente do sexo e do grupo racial, tiveram oportunidades iguais para se infectarem com B. c. vogeli, confirmando que o sexo e o grupo racial não são fatores de risco para a infecção. O mesmo foi observado em relação aos animais que eram submetidos ao controle de carrapatos. Embora o controle de carrapato seja feito por alguns proprietários, possivelmente, ele não é realizado de forma que permita de fato o controle da população do vetor, quer seja pela falha no tratamento ou utilização de dosagens inadequadas. Os achados em relação ao sexo e ao grupo racial concordam com a maioria dos estudos epidemiológicos realizados para babesiose canina (YAMANE et al., 1994; GUIMARÃES et al., 2002; MAIA et al., 2007; GUIMARÃES et al., 2009). 
Tabela 1: Distribuição da frequência das variáveis área, sexo, faixa etária, raça, controle de carrapatos em cães positivos para Babesia canis vogeli da microrregião de Imperatriz-MA

\begin{tabular}{|c|c|c|c|c|c|c|c|c|}
\hline \multirow{2}{*}{ Variável } & \multicolumn{3}{|c|}{$\begin{array}{c}\text { Positivo } \\
\text { Babesia canis vogeli }\end{array}$} & \multicolumn{2}{|c|}{$\begin{array}{c}\text { Negativo } \\
\text { Babesia canis vogeli }\end{array}$} & \multirow[t]{2}{*}{ Total } & \multirow[t]{2}{*}{ OR } & \multirow[t]{2}{*}{ IC } \\
\hline & & $\mathrm{N}$ & $\%$ & $\mathrm{~N}$ & $\%$ & & & \\
\hline \multirow[t]{2}{*}{ Área } & Urbana & 3 & 2 & 147 & 98 & 150 & $0,42^{\mathrm{a}}$ & $0,08-1,83$ \\
\hline & Rural & 7 & 4,66 & 143 & 95,34 & 150 & & \\
\hline \multirow{3}{*}{ Sexo } & $\mathrm{M}$ & 8 & 4,62 & 165 & 95,38 & 173 & $3,03^{\mathrm{a}}$ & $0,58-21,04$ \\
\hline & F & 2 & 1,57 & 125 & 98,43 & 127 & & \\
\hline & $<1$ ano & 5 & 8,48 & 54 & 91,52 & 59 & $8,06^{\mathrm{a} *}$ & $0,88-187,23$ \\
\hline \multirow[t]{2}{*}{ Faixa etária } & $1-3$ anos & 4 & 2,62 & 149 & 97,38 & 153 & & \\
\hline & $>3$ anos & 1 & 1,14 & 87 & 98,86 & 88 & & \\
\hline \multirow[t]{2}{*}{ Raça } & SRD & 9 & 3,30 & 263 & 96,70 & 272 & $0,92^{\mathrm{a}}$ & $0,11-20,20$ \\
\hline & CRD & 1 & 3,57 & 27 & 96,43 & 28 & & \\
\hline \multirow[t]{2}{*}{$\begin{array}{l}\text { Controle de } \\
\text { carrapatos }\end{array}$} & Sim & 3 & 1,82 & 162 & 98,18 & 165 & $0,34^{\mathrm{a}}$ & $0,07-1,49$ \\
\hline & Não & 7 & 5,18 & 128 & 94,82 & 135 & & \\
\hline
\end{tabular}

(M) machos, (F) fêmeas, (a) Exato de Fisher, (*) Diferença significativa p<0,05, OR=Odds ratio, IC= Intervalo de Confiança, $(\mathrm{SRD})=$ Sem raça definida, $(\mathrm{CRD})=$ Com raça definida

Cães com raça definida apresentaram chances iguais de contrair a infecção quando comparados aos cães sem raça definida, concordando com YAMANE et al. (1994) ao relatarem que, sob o mesmo manejo, eliminando-se as particularidades inerentes à rotina diária de atividades as quais os cães são submetidos, provavelmente não seriam observadas diferenças de susceptibilidade de acordo com as raças. Essas observações também concordam com os resultados de GUIMARÃES et al. (2009).

Dos 369 espécimes de $R$. sanguineus identificados, 235 foram submetidos a PCR para pesquisa de $B$. $c$. vogeli. Destes, $6(2,56 \%)$ estavam positivos para B. c. vogeli (Figura 2), sendo $1,28 \%$ (3/235) provenientes de cães da área urbana e 1,28\%
(3/235) de cães da área rural. No município de Imperatriz, um carrapato era da área urbana e dois carrapatos da área rural. Em Davinópolis, um carrapato era da área rural e outros dois provenientes da área urbana. Não houve carrapato positivo para a pesquisa de B. c. vogeli no município de Governador Edison Lobão.

Em relação ao sexo dos carrapatos, os seis exemplares positivos para B. c. vogeli eram machos. As seis espécimes de carrapatos positivos para B. $c$. vogeli foram coletados de cães que apresentaram PCR do sangue negativo. Provavelmente, esses espécimes de carrapatos, foram coletadas dos cães antes da inoculação do agente pelo carrapato.

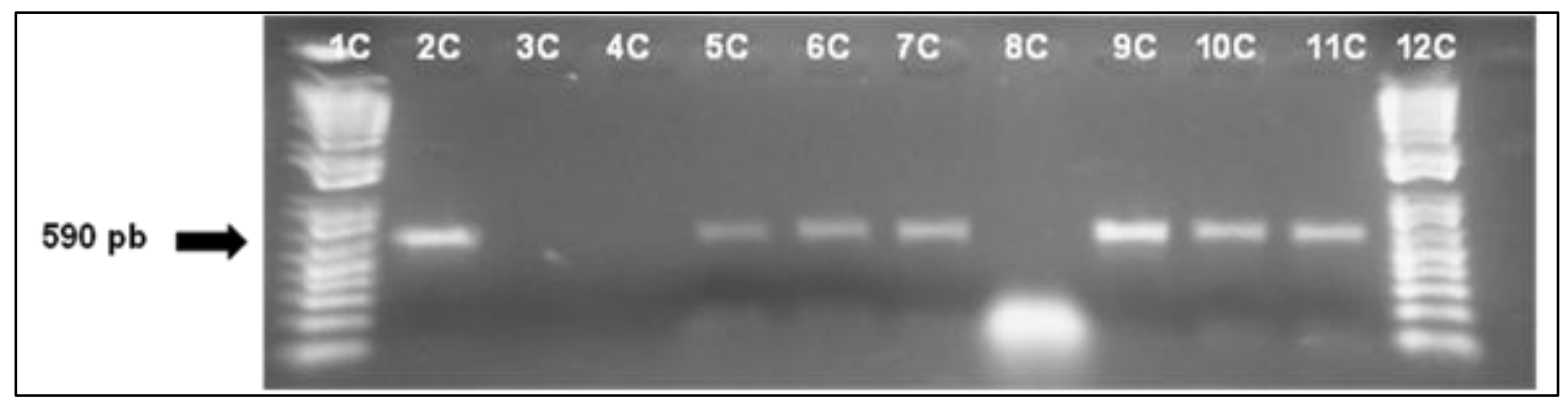

Figura 2: Gel de agarose 1,5\% corado com brometo de etídeo, mostrando resultados de produto amplificado de PCR, utilizando-se os oligonucleotídeos iniciadores BAB1 e BAB4, que amplificam uma região de 590 $\mathrm{pb}$, referente ao gene 18S rRNA, específico para Babesia canis vogeli. Linhas 1C e 12C: marcador de peso molecular 1Kb; Linha 2C: controle positivo; Linha 3C: controle negativo; Linha 4C: controle do Mix; Linhas 5C, 6C, 7C, 9C, 10C e 11C: correspondem a amostras de Rhipicephalus sanguineus positivas para $B$. $c$. vogeli, coletadas de cães da Microrregião de Imperatriz-MA. 
A detecção de espécies do gênero Babesia por PCR em espécies de carrapatos tem sido amplamente utilizada em estudos epidemiológicos em diversos países (INOKUMA et al., 2003; MATJILA et al., 2005; M'GHIRBI \& BOUATTOUR, 2008), mas, estudos envolvendo a pesquisa de $B$. canis diretamente no vetor são escassos no Brasil. M'GHIRBI \& BOUATTOUR (2008), em estudo realizado na Tunisia, obtiveram prevalência de $0,6 \%(1 / 160)$ de $R$. sanguineus infectados com B. c. vogeli, sendo inferior à obtida neste estudo. Contudo, a dinâmica de populações de carrapatos é dependente das condições climáticas afetando, assim, a transmissão da Babesia spp. e, consequentemente, a sua manutenção na natureza (FRIEDHOFF, 1988). Ressalta-se que a microrregião de Imperatriz apresenta condições favoráveis para o ciclo de vida do vetor embora com diferenças sazonais.

\section{CONCLUSÃO}

Este estudo confirmou a presença de $B$. $c$. vogeli em cães e em $R$. sanguineus na área urbana $\mathrm{e}$ rural da microrregião de Imperatriz, Estado do Maranhão. Não foram verificadas associações entre ambiente de coleta, grupo racial, sexo e controle de carrapatos; contudo, a infecção foi mais frequentemente detectada por PCR nos animais jovens.

\section{REFERÊNCIAS}

ARAGÃO, H.; FONSECA, F. Notas de ixodologia. VIII Lista e chave para os representantes da fauna ixodológica brasileira. Memórias do Instituto Oswaldo Cruz, v.59, n.2, p.115-129, 1961.

BOBADE, P. A.; ODUYE, O. O.; AGHOMO, H. O. Prevalence of antibodies against Babesia canis in dogs in an endemic area. Revue d'Élevage et de Médecine Vétérinaire des Pays Tropicaux, 42, 211-217, 1989.

BOOZER, A. L.; MACINTIRE, D. K. Canine babesiosis. Veterinary Clinics of North America: Small Animal, v. 33, n.4, p. 885-904, 2003.

BIRKENHEUER, A. J.; NEEL, J.; RUSLANDER, D.; LEVY, M. G.;BREITSCHWERDT, E. B. Detection and molecular characterization of a novel large Babesia species in a dog. Veterinary Parasitology, v.124, p.151160, 2004.

CACCIO', S. M., ANTUNOVIC, B., MORETTI, A., MANGILI, V., MARINCULIC, A., BARIC, R. R., SLEMANDA, S. B., PIENIAZEK, N. J., Molecular characterization of Babesia canis canis and Babesia canis vogeli from naturally infected European dogs. Veterinary Parasitology, v.106, p.285-292, 2002.
CARRET, C; WALLAS, F.; CARCY, B.; GRANDE, N.; PRÉCIGOUT, E., MOUBRI, K.;SCHETTTERS, T. P.; GORENFLOT, A. Babesia canis canis, Babesia canis vogeli, Babesia canis rossi: Differentiation of the three subspecies by a Restriction Length Polymorphism Analysis on Amplified Small Subunit Ribossomal RNA genes. Journal of Eukaryotic Microbiology, v. 46, n. 3, p. 298-303, 1999.

CHOMEKZYNSK, P. A reagent for the single-step simultaneous isolation of RNA, DNA and proteins from cell and tissue samples. BioTechniques, v. 153, n. 3, p. 532-537, 1993.

COSTA-JÚNIOR, L. M., RIBEIRO, M. F. B., REMBECK, K., RABELO, E. M. L., ZAHLER-RINDER, M., HIRZMANN, J., PFISTER, K., PASSOS, L. M. F. Factors associated with seroprevalence of canine babesiosis caused by Babesia vogeli in rural areas of the State of Minas Gerais, Brazil. Research in Veterinary Science, v.86, p.257-260, 2009.

DANTAS-TORRES, F.; L. A. FIGUEREDO. Canine babesiosis: a Brazilian perspective. Veterinary Parasitology, v. 141, p.197-203, 2006.

DELL'PORTO, A.; OLIVEIRA, M.; MIGUEL, O. Babesia canis in stray dogs of the city of São Paulo. Comparative studies between the clinical and hematological aspects and the indirect fluorescent antibody test. Revista Brasileira de Parasitologia Veterinária, v. 2, n. 1, p. 37-40, 1993.

DUARTE, S. C.; LOULY C. C. B.; SILVEIRA NETO, O. J.; ROMANOWSKI, T. N. A.; LINO JUNIOR, R. S.; LINHARES G. F. C. Diagnóstico parasitológico e molecular da babesiose canina na cidade de Goiânia-GO. Revista de Patologia Tropical, v.37, n.3, 229-236, 2008a.

DUARTE, S. C.; LINHARES, G. F. C.; ROMANOWSKY, T. N.; SILVEIRA NETO, O. J.; BORGES, L. M. F. Assessment of primers designed for the subspecies-specific discrimination among Babesia canis canis, Babesia canis vogeli and Babesia canis rossi by PCR assay. Veterinary Parasitology, v.152, p.16-20, 2008b.

FRIEDHOFF, K. T. Transmission of Babesia. In: RISTIC, $M$. Babesiosis of domestic 5 animals and man. Boca Raton: CRC Press, 1988. p. 23-52.

FURUTA, P. I.; OLIVEIRA, T. M. F. S; TEIXEIRA, M. C. A.; ROCHA, A. G.; MACHADO, R. Z.; TINUCCICOSTA, M. Comparison between a soluble antigen-based ELISA and IFAT in detecting antibodies against Babesia canis in dogs. Revista Brasileira de Parasitologia Veterinária, v. 18, n. 3, p. 41-45, 2009.

GUIMARÃES, A. M.; OLIVEIRA, T. M. F. S.; SANTA ROSA, I. C. A. Babesiose canina: uma visão dos clínicos veterinários de Minas Gerais. Clínica Veterinária, ano 8, n. 41, p. 60-68, 2002.

GUIMARÃES, A. M.; ROCHA, C. M. B. M.; OLIVEIRA, T. M. F. S.; ROSADO, I. R.; MORAIS, L. 
G.; SANTOS, R. R. D. Fatores associados à soropositividade para Babesia, Toxoplasma, Neospora e Leishmania em cães atendidos em nove clínicas veterinárias do município de Lavras, MG. Revista Brasileira de Parasitologia Veterinária, v. 18, supl. 1, p. 49-53, 2009.

INOKUMA, H.; YOSHIZAKI, Y.; SHIMADA, Y.; SAKATA, Y.; OKUDA, M.; ONISHI, T. Epidemiological survey of Babesia species in Japan performed with specimens from ticks collected from dogs and detection of new Babesia DNA closely related to Babesia odocoilei and Babesia divergens DNA. Journal of Clinical Microbiology, v.41, p.3494-3498, 2003.

MAIA, M.G.; COSTA, R.T.; HADDAD, J.P.; PASSOS, L.M.; RIBEIRO, M.F. Epidemiological aspects of canine babesiosis in the semiarid area of the state of Minas Gerais, Brazil. Preventive Veterinary Medicine, 79, 155-162, 2007.

MATJILA, P. T.; NIJHOF, A. M.; TAOUFIK, A.; HOUWERS, D.; TESKE, E.; PENZHORN, B.L.; DE LANGE, T.; JONGEJAN, F.; Autochthonous canine babesiosis in The Netherlands. Veterinary Parasitology, v.131, p.23-29, 2005.

MATJILA, P. T.; PENZHORN, B. L.; BEKKER, C. P. J.; NIJHOF, A. M.; JONGEJAN, F.; Confirmation of occurrence Babesia canis vogeli in domestic dogs in South Africa. Veterinary Parasitology, v.122, p.119-125, 2004.

M'GHIRBI, Y.; BOUATTOUR, A. Detection and molecular characterization of Babesia canis vogeli from naturally infected $\operatorname{dogs}$ and Rhipicephalus sanguineus ticks in Tunisia. Veterinary Parasitology, v. 152, n. 1-2, p.1-7, 2008.

O'DWYER, L. H.;LOPES, V. V. A.; RUBINI, A, S.; PADUAN, K. S.; RIBOLLA, P. E. M. Babesia spp. infection in dogs from rural areas of São Paulo State, Brazil, Revista Brasileira de Parasitologia Veterinaria, v. 18, n. 2, p. 23-26, 2009.

PASSOS, L. M. F.; GEIGER, S. M.; RIBEIRO, M. F. B.; PFISTER, K.; ZAHLER-RINDER., M. First molecular detection of Babesia vogeli in dogs from Brazil. Veterinary Parasitology, v. 127, p. 81-85, 2005.

PRATT, H. D. Chave pictórica para identificação de gêneros de carrapatos adultos do Brasil, Modificada de Harry Pratt (Departamento of Health, Education and Welfare, Public Health Service, Centers for Disease Control-CDC, Atlanta, 1961). Disponível em: <http://www.cdc.gov/nceh/ehs/Docs/Pictorial_Keys/Ticks .pdf>. Acesso em: 08 Jan. 2012.

RAMOS, R.; RAMOS, C.; ARAÚJO, F.; OLIVEIRA, I.; PIMENTEL, D.; GALINDO, M.; SANTANA, M.; ROSAS, E.; FAUSTINO, M.; ALVES, L. Molecular survey and genetic characterization of tick-borne pathogens in dogs in metropolitan Recife (north-eastern Brazil). Parasitology Research, v 107, p. 1115-1120, 2010 .
ROCHA, A. L.; MELO, S. A.; OLIVEIRA, M. S.; SOBRINHO, I. C. M.; CORRÊA, R. S. F. P.; MILHOMEM, M. N.; TORRES, D. B. A.; ABREUSILVA, A. L; ANDRADE, F. H. E. Detecção molecular de Babesia canis vogeli em cães residentes em duas localidades São Luis, Estado do Maranhão, Brasil. In: $38^{\circ}$ CONGRESSO BRASILEIRO DE MEDICINA VETERINÁRIA, 799. 2011. Florianópolis, SC, Anais... Florianópolis, 2011. Disponível em: < http://www.sovergs.com.br/site/38conbravet/resumos/799. pdf>. Acesso em: 05 Abr. 2012.

SÁ, A. G.; CERQUEIRA, A. M. F.; O'DWYER, L. H.; MACIEIRA, B. M.; ABREU, F. S.; FERREIRA, F. R.; PEREIRA, A. M.; VELHO, P. B.; ALMOSNY, N. R. P. Detection and molecular characterization of Babesia canis vogeli from naturally infected brazilian dogs. The International Journal of Applied Research in Veterinary Medicine, v. 4, n. 2, p.163-168, 2006.

SANGIONI, L. A.; HORTA, M. C.; VIANNA, M. C. B.; GENNARI, S. M.; SOARES, R. M.; GALVÃO, M. A. M.; SCHUMAKER, T. T. S.; FERREIRA, F.; VIDOTTO, O.; LABRUNA, M. B. Rickettsial infection in animals and Brazilian spotted fever endemicity. Emerging Infectious Diseases, v. 11, n. 2, p. 265-270, 2005.

SZABÓ, M. P. J.; CUNHA, T. M. PINTER, A.; VICENTINI, F. Ticks (Acari: Ixodidae) associated with domestic dogs in Franca region, São Paulo, Brazil, Experimental and Applied Acarology, v. 25, p. 909916, 2001

SHIMADA, Y.; BEPPU, T.; INOKUMA, H.; OKUDA, M.; ONISHI, T. Ixodid tick species recovered from domestic dogs in Japan. Medical and Veterinary Entomology, v. 17, n. 1, p.38-45, 2003.

TABOADA, J.; MERCHANT, S. R. Babesiosis of companion animals and man. Veterinary Clinics of North America: Small Animal, v. 21, n. 1, p. 47-50, January 1991.

TABOADA, J.; MERCHANT, S. R. Infecções por protozoários e por outras causas. In: ETTINGER, S. J.; FELDMAN E. C. Tratado de medicina interna veterinária. 4.ed. São Paulo: Manole, v.1, cap.68, 1997. p.554-572.

TRAPP, S. M.; DAGNONE, A. S.; VIDOTTO, O.; FREIRE, R. L.; AMUDE, A. M.; MORAIS, H. S. A. Seroepidemiology of canine babesiosis and ehrlichiosis in a hospital population. Veterinary Parasitology, v. 140, p. 223-230, 2006a.

TRAPP, S. M.; MESSICK, J. B.; VIDOTTO, O. JOJIMA, F. S.; MORAIS, H. S. M. Babesia gibsoni genotype Asia in dogs from Brazil. Veterinary Parasitology, v.141, p.177-180, 2006b.

UNGAR DE SÁ, M. F. M.; UNGAR DE SÁ, J. E.; BITTENCOURT, D. V. V; BISPO, A.C.; RÉGIS, A. M. M.; SOUZA FILHO, N. J.; GOMES NETO, C. M. B.; SOUZA, B. M.P. S.; BITTENCOURT, T. C. C.; FRANKE, C. R.Estudo retrospectivo (1991-2005), dos 
caos de babesiose canina na cidade de Salvador e Região Metropolitana, Bahia. Revista Brasileira de Saúde e Produção Animal, v. 8, n. 3, p. 178-183, 2007.

YAMANE, I. J. W., THOMFORD, J. W.; GARDNER, I. A. Evaluation of the indirect fluorescent antibody test for diagnosis of Babesia gibsoni infections in dogs. American Journal of Veterinary Research, v.54, p.1579-1584, 1993.

YAMANE, I.; GARDNER, I. A.; RYAN, C. P.; LEVY, M.; URRICO, J.; CONRAD, P. A. Serosurvey of Babesia canis, Babesia gibsoni and Erlichia canis in pound dogs in California, USA. Preventive Veterinary Medicine, v.18, p. 293-304, 1994.

WAGNER, G.; CRUZ, D.; HOLMAN, P.; WAGHELA, S.; PERRONE, J.; SHOMPOLE, S.; RURANGIRWA, F.

NON-immunologic methods of diagnosis of babesiosis. Memórias do Instituto Oswaldo Cruz, v. 87, Suppl 3, p.193-9, 1992.

ZAHLER, M., E.; SCHEIN, H.; RINDER,I; GOTHE. Characteristic genotypes discriminate between Babesia canis isolates of differing vector specificity and pathogenicity to dogs. Parasitology Research, v. 84, p. 544-548, 1998.

Protocolado em: 06 maio de 2012. Aceito em: 29 jun. 2012. 